\title{
Aprender pensando: metodologías artísticas para la escuela
}

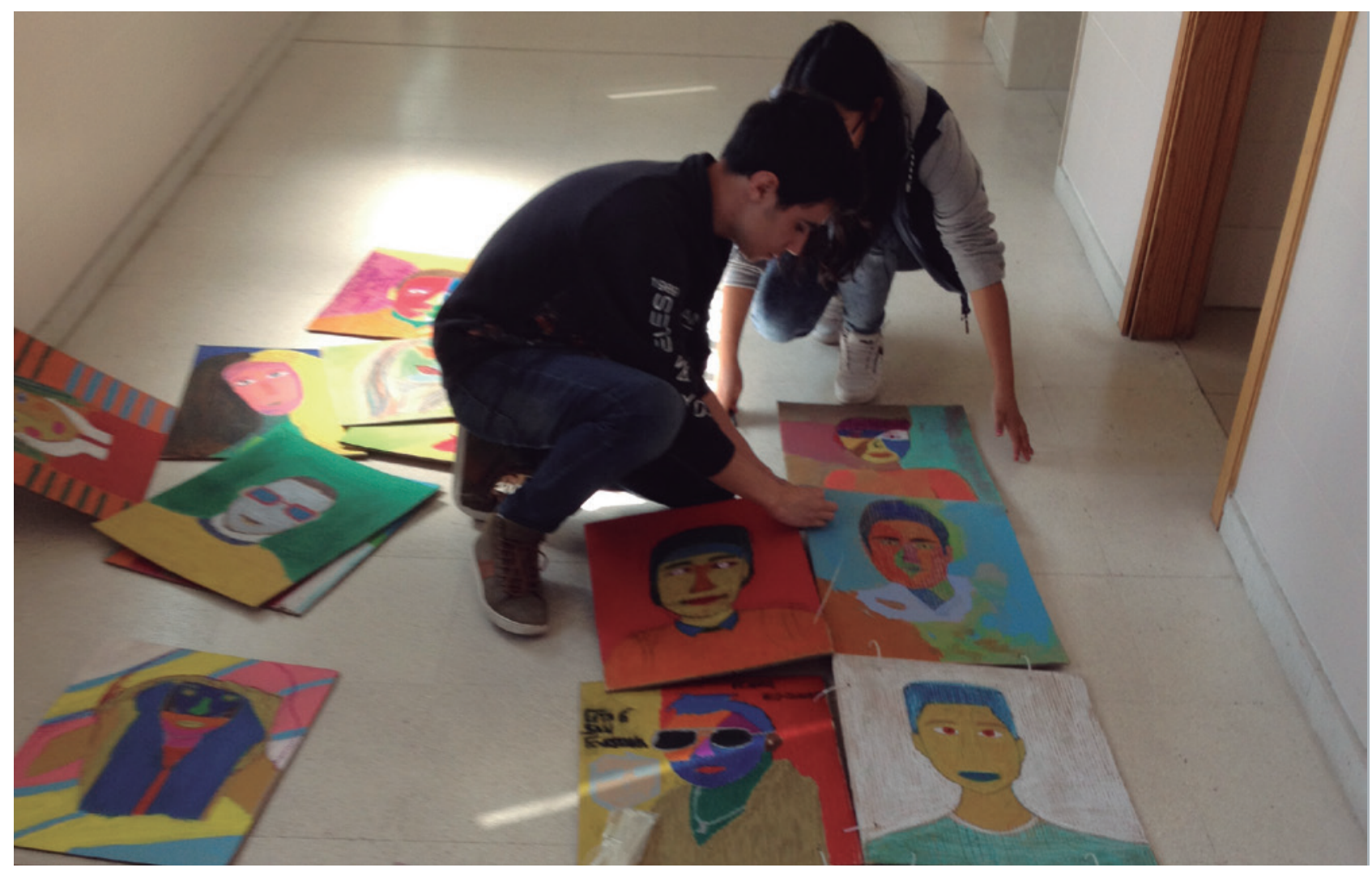

La educación artística está cambiando la situación del aprendizaje en la escuela. Las nuevas metodologías artísticas conciben un currículo educativo que se enmarca en los procesos creativos que permiten un aprendizaje activo y significativo. La multidisciplinariedad del arte ayuda a los docentes a desarrollar metodologías que favorecen la interacción, la manipulación, la experimentación e interiorización de contenidos curriculares desde el juego y la resolución de problemas. Conecta conocimientos, relaciona y valora, es crítica con el entorno y hace propuestas para la transformación social. 


\section{La cultura visual en la escuela}

La escuela del siglo XXI se encuentra inmersa en un proceso de transformación que abandona una enseñanza basada en la memorización y los contenidos. Se tiende hacia un aprendizaje de competencias que permiten gestionar el conocimiento poniéndolo en relación con la cultura y la sociedad. El proceso se da en una cultura compleja, plural e "hipervisual" que se centra en la producción e intercambio de contenidos audiovisuales como modo de conocer la realidad. Como consecuencia de eso, nuestros hijos y alumnos consumen una gran cantidad de imágenes y participan de una gran cantidad de imaginarios colectivos (el de Disney, las series de animación, los videojuegos, los universos de los superhéroes, juguetes y merchandising...) mientras que en los contextos escolares se elimina paulatinamente la educación artística, reforma tras reforma, de la ley educativa.

Pero el arte no se resiste a desaparecer de la escuela. A través de otras disciplinas como las tecnologías de la información y la comunicación, la gamificación, las tecnologías audiovisuales, etc., se hace presente en formatos muy diversos, desde vídeos, imágenes, instalaciones artísticas, performance, etc.

Las distintas transformaciones de la, comúnmente llamada, innovación educativa, que utiliza en muchos casos estas herramientas antes nombradas, nos hacen caer en la cuenta que la educación artística y las metodologías artísticas en la escuela son cada vez más necesarias. Es necesario, en palabras de María Acaso, incorporar el aprendizaje artístico y visual en la escuela para construir ciudadanía implicada con el presente y futuro de sus sociedades. Así evitaremos que nuestros hijos e hijas terminen siendo analfabetos visuales sin criterios para una mirada crítica social.

Nos podemos preguntar qué tiene de especial aprender a través del arte (como ya pronosticó Rudolf Arheim en los años 70 del siglo XX) y por qué es fundamental para la educación del siglo XXI. Daré cuatro razones que pueden justificar esta afirmación:

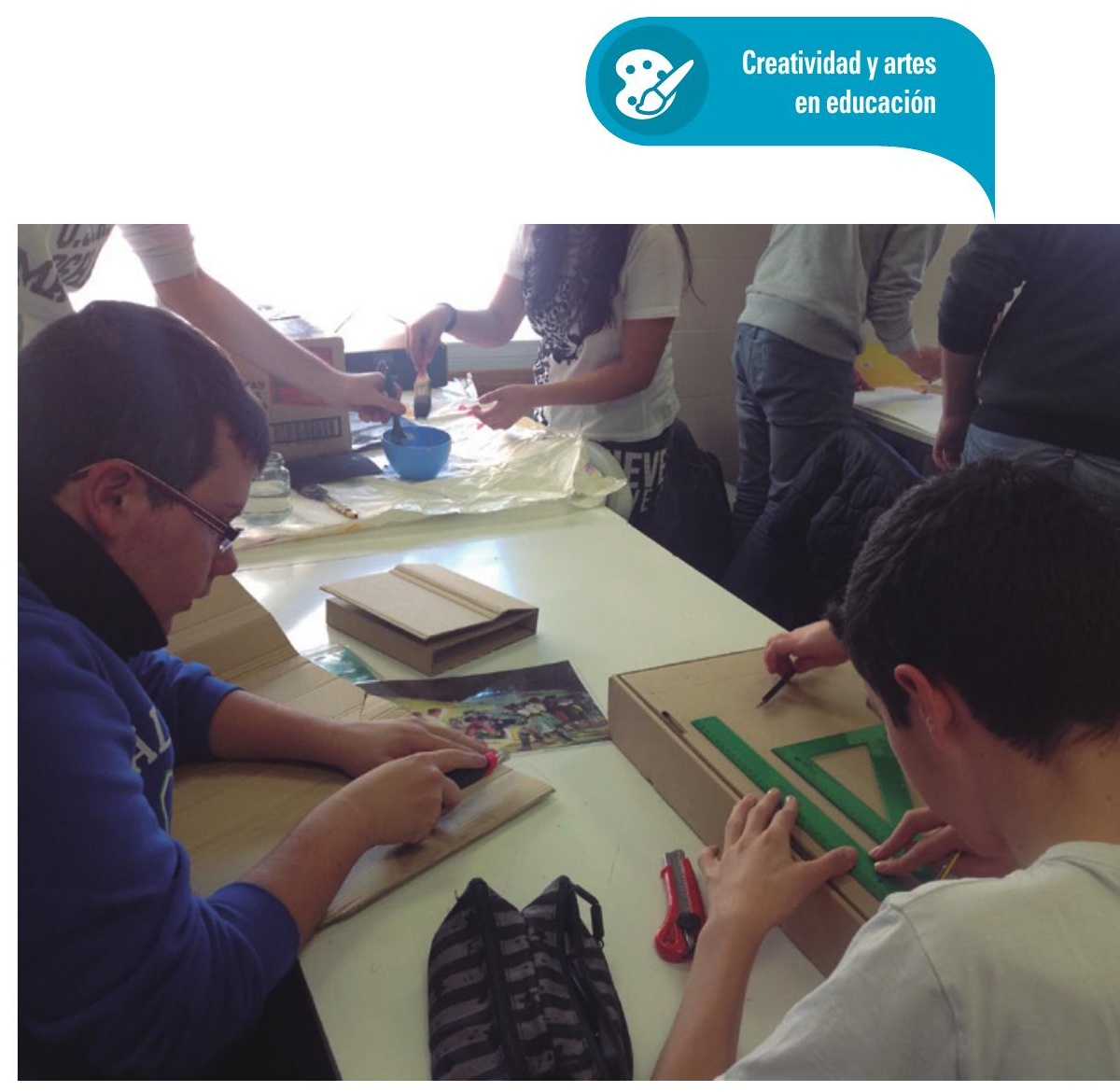

Primero, nuestra forma de pensar hasta el siglo XX en occidente ha sido lineal, lógica, unidireccional, cerrada, mientras que la pluralidad del siglo XXI nos sitúa en un pensamiento en red, subjetivo, multidireccional, abierto y crítico. Estas características son propias de las artes, que abordan la creación como un proceso multidimensional para intervenir un problema y darle solución.

Segundo, a lo largo de los descubrimientos educativos del siglo XX los educadores han descubierto la necesidad de integrar las artes y su expresión en los procesos de aprendizaje, como una herramienta de placer y juego. El cuerpo también es protagonista del aprendizaje. A través de él se produce la percepción del entorno y desencadena los procesos cognitivos que construyen las relaciones entre el conocimiento y la realidad. Un cuerpo que no se mueve, sujeto a una siIla, una clase, que evita tocar y manipular tiene grandes dificultades de aplicar lo aprendido en la vida cotidiana.

Tercero, hemos de recuperar el sentido de la educación, en cuanto que no es un acto de instrucción y homogenización social, sino un acto político de comprender la cultura que nos rodea y producir la cultura que nuestra generación y las generaciones futuras disfrutarán. Se trata de recuperar la responsabilidad sobre el lugar en el que vivimos, siendo conscientes de que todos 
lenguajes tradicionales de la escuela) en la cultura cotidiana, por lo que es necesario recuperar la capacidad simbólica de la persona, vinculada íntimamente al lenguaje audiovisual y al arte contemporáneo, en las experiencias de enseñar y aprender que se dan en la escuela.

\section{Educar con metodologías artísticas}

Teniendo esto en cuenta, hemos dado un salto de enseñar arte (cuando el arte estaba en los museos) a aprender con el arte, ahora que el arte está en el centro de nuestra cultura. Me gustaría describir algunas de estas metodologías artísticas que colaboran en los procesos de aprendizaje del hoy. Con ellas se potencia el pensamiento creativo e innovador en el alumnado y su capacidad de trabajar con otros. Y a la vez, se desarrolla su mirada crítica y su autonomía. Las agruparé en tres grandes grupos de metodologías: las que tienen que ver con metodologías de diseño y proyectos (pensamiento creativo), las metodologías centradas en el pensamiento visual y las metodologías que tienen que ver con la acción o performáticas (pensamiento activo).

\section{Aprender con metodologías de diseño}

Las metodologías de diseño o proyectos tienen que ver con el pensamiento creativo, capaz de dar soluciones a problemas. En estas situaciones los alumnos aprenden a definir el problema, investigar sobre él, analizarlo y proponer soluciones desde el diseño y la planificación. Por ejemplo, se plantea la necesidad hipotética de diseñar una tienda, una empresa, una galería de arte o una casa, y a partir de ahí se comienzan a desarrollar ideas y tomar decisiones para llegar a un proyecto concreto y un producto final. Las soluciones finales van a ser variadas, en función de los participantes y la capacidad que estos vayan desarrollando e interaccionando en el proceso.

Estas metodologías surgieron en los años 70 en las escuelas de diseño y artes, pero a lo largo de las décadas siguien-

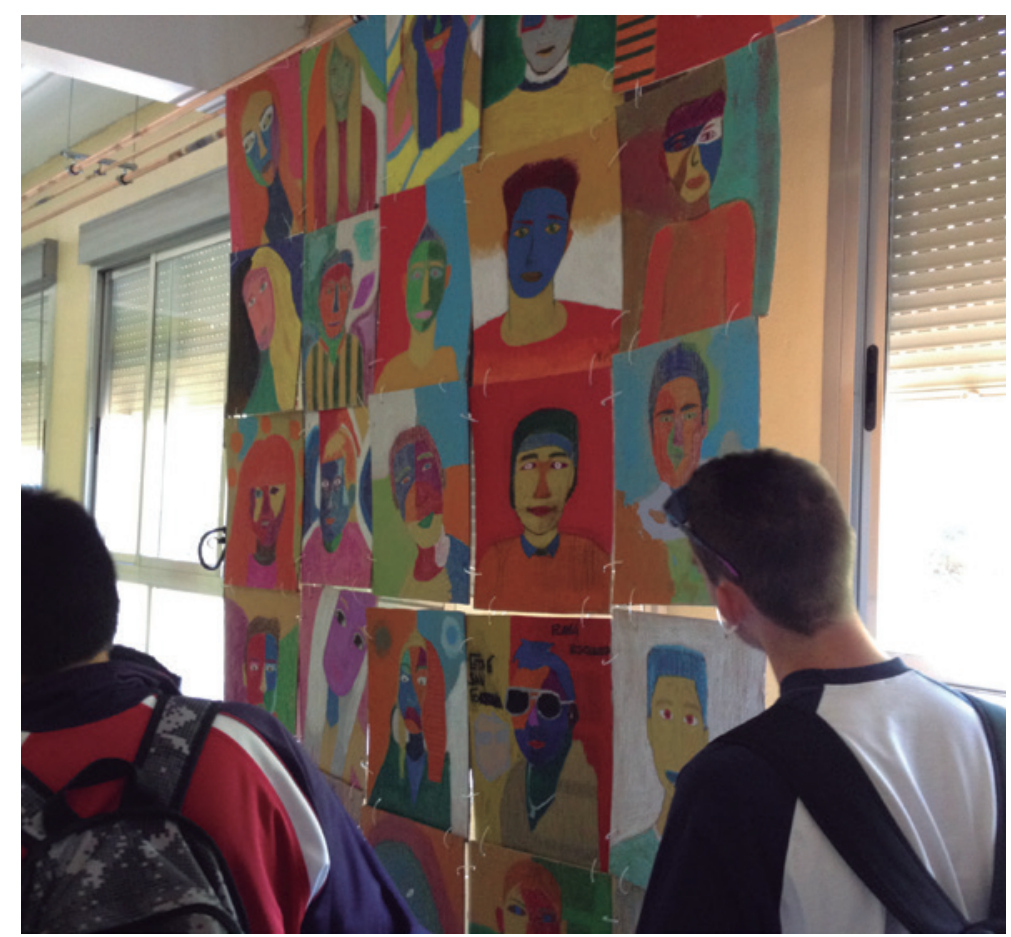

tes se han ido incorporando a las pedagogías escolares. Por ejemplo, el design thinking suele investigar problemas que no están claramente definidos, obteniendo información, analizando contenidos y proponiendo soluciones en los campos del diseño y la planificación. Combina el conocimiento y compresión del contexto en el que surgen los problemas con la creatividad, para presentar propuestas novedosas que den solución a los problemas de una forma razonable. La metodología parte de un pensamiento divergente y objetivos difusos, para llegar a soluciones prácticas, conseguidas a través de un pensamiento convergente. El design thinking combina la empatía, la imaginación, la experimentación, el prototipado colectivo, el pensamiento integrador y el aprendizaje interactivo.

Esta metodología se aplicó en la enseñanza en los años 80 del siglo XX por Doreen Nelson en California con el nombre de aprendizaje basado en el diseño (ABD - DBL, design-based learning). Se trata de crear un entorno escolar que combine en el proceso de aprendizaje varias disciplinas, las asociadas al diseño (artes, arquitectura, ingeniería, diseño gráfico) y otras que no (ciencia, tecnología y humanidades). Es una metodología que desarrolla competencias de la comunicación y colaboración, pero que además fomenta el aprendizaje profundo a través de lo 


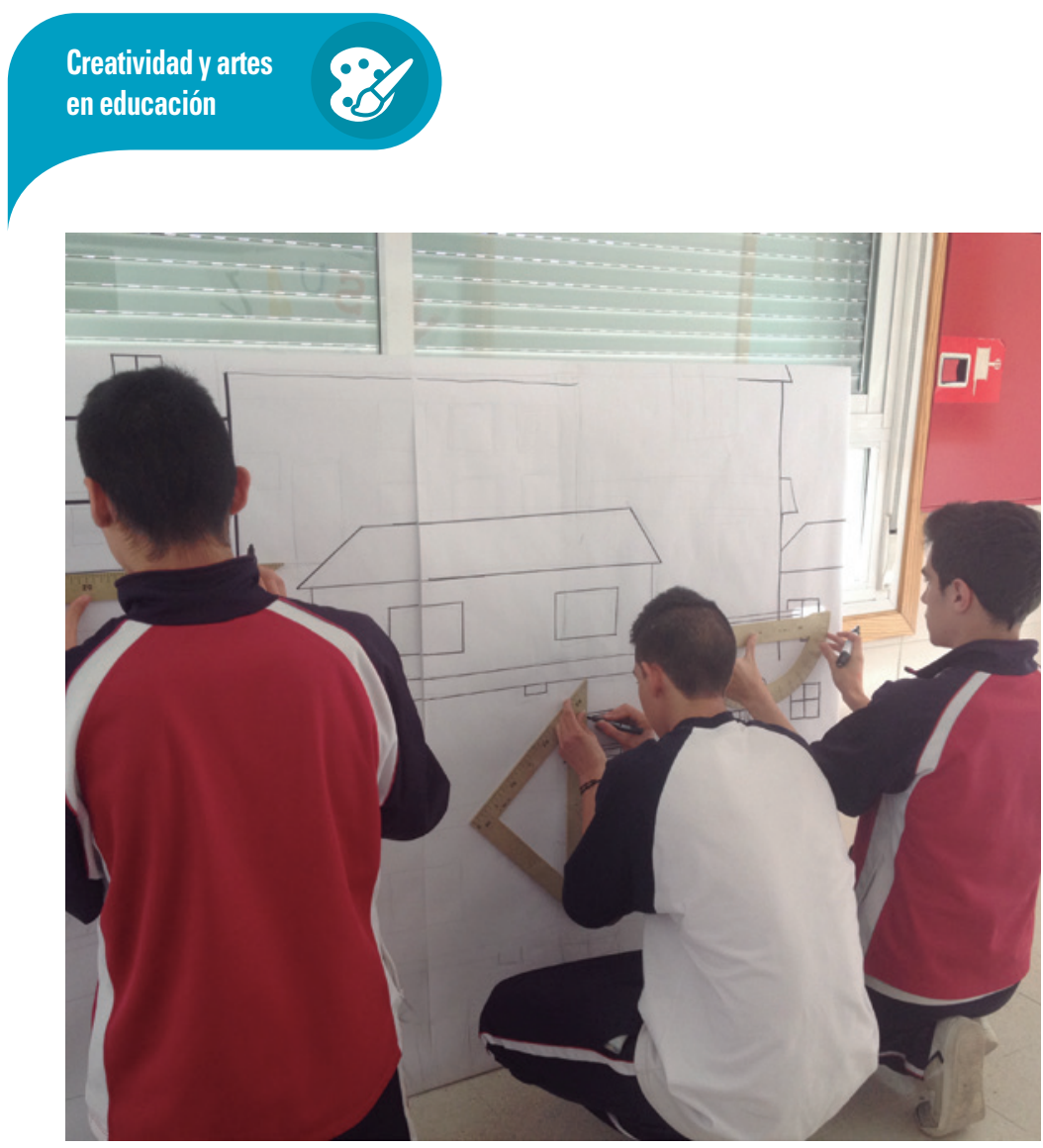

interactivo y lo experimental. EI ABD potencia el proceso de interacción entre los estudiantes que crean, prueban, evalúan y rediseñan sus proyectos.

La diferencia principal con otros métodos de aprendizaje como el aprendizaje basado en proyectos o aprendizaje basado en problemas (PBL), es el hecho de que en el ABD situamos al estudiante, en grupo, en un contexto, con el cual debe hacerse las preguntas necesarias para encontrar y solucionar problemas. En cambio, en el aprendizaje basado en proyectos, el profesor plantea las metas y problemas a resolver, al igual que en el aprendizaje basado en problemas, por lo que la iniciativa es del profesor y no del alumnado, además de tener un solo resultado final. En el ABD lo importante es el proceso, que es donde se adquieren las competencias, y no la meta. Los beneficios que se observan en los estudiantes son: el desarrollo de los procesos de comprensión y aplicación del conocimiento, el desarrollo de sus propias ideas y la ampliación del rango de pensamiento en relaciones y asociaciones, mayor que las del método tradicional de investigación guiada.

\section{Aprender con metodologías de pensamiento visual}

El pensamiento visual (visual thinking) está muy relacionado con la innovación ya que el objetivo último de este pensa-

miento es mejorar los sistemas o ideas interrelacionadas que creamos en nuestra mente. La innovación pedagógica actual trabaja con "hipótesis", por lo que el pensamiento visual se convierte en la mejor metodología para desarrollar y contrastar esas hipótesis. El pensamiento visual se puede utilizar para resolver, estudiar y explorar conceptos y sistemas, para entender visualmente cómo funcionan e innovar sobre ellos.

Se trata de un aprendizaje visual que favorece el uso de organizadores gráficos (métodos visuales para ordenar información) con el objeto de ayudar a los estudiantes a pensar y a aprender más efectivamente. Los organizadores gráficos pueden ser al mismo tiempo recursos del docente y herramientas para el aprendizaje del alumnado. Sirven para reforzar contenidos, pero también para desarrollar habilidades como la ordenación, comparación, discriminación o categorización. Permiten identificar ideas erróneas, visualizar patrones o interrelaciones entre ideas o conocimientos, incluso distinguir factores necesarios o prescindibles para que algo se dé.

Las metodologías del visual thinking pueden ser técnicas de mapeo, como los diagramas o árboles visuales que ayudan al alumnado a procesar, organizar, priorizar, retener y recordar nueva información, para poder adquirirla mejor. También las representaciones gráficas con iconos o dibujos, el uso de la fotografía para la explicación de contenidos, las asociaciones de ideas mediante imágenes como los bits de inteligencia, o la infografía (mapas visuales). Otra forma de visual thinking son los storytellings que van mas allá de lo que cuentan y se fijan en nosotros a través de emociones. Al vincular una emoción con un contenido, se eleva el nivel de recuerdo y se facilita la ampliación del mismo con otros conocimientos.

El pensamiento visual estimula el pensamiento creativo y predispone al alumnado a colaborar en proyectos colaborativos y de diseño y resolución de problemas. De forma resumida, las dife- 


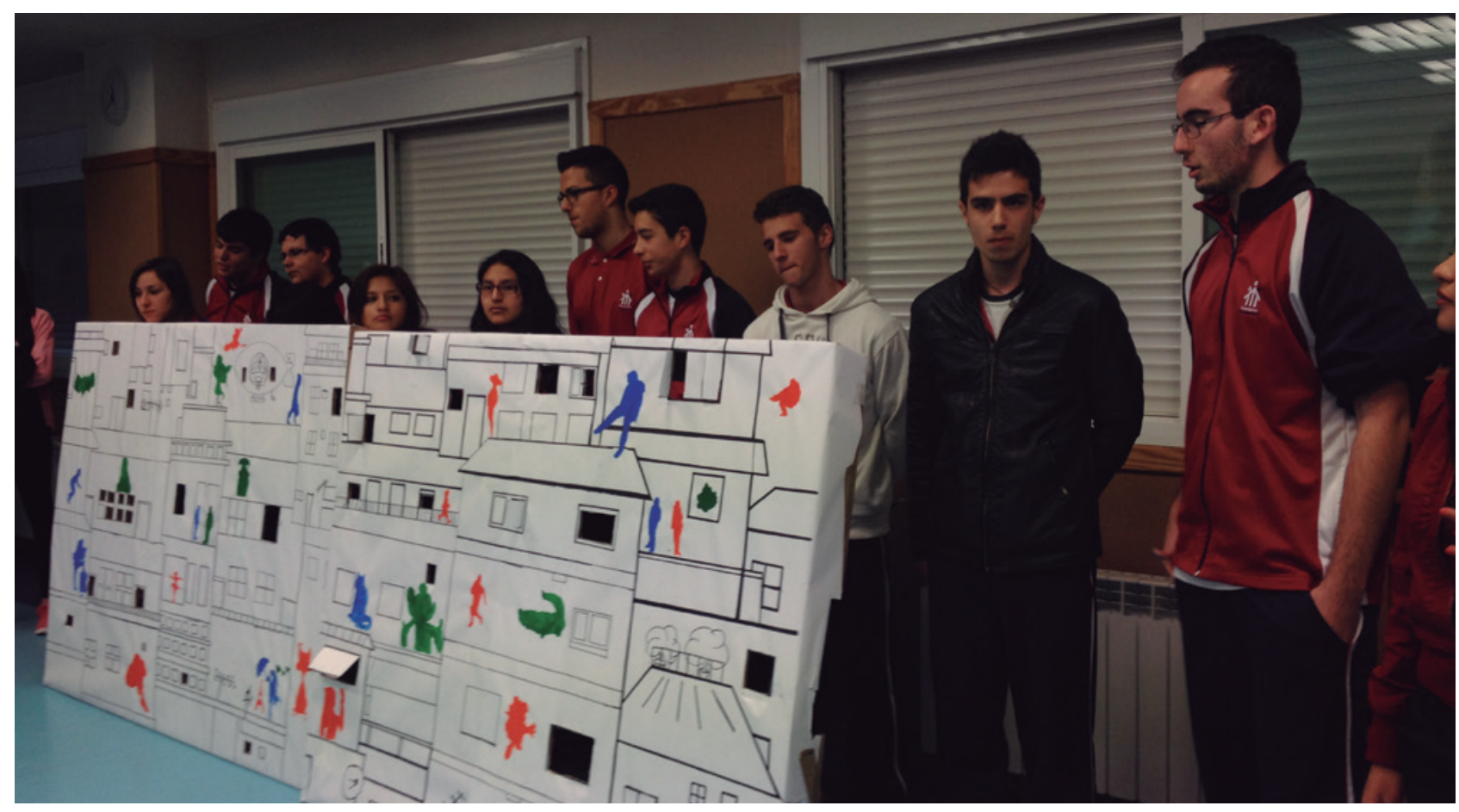

rentes estrategias del pensamiento visual contribuyen a:

1. Clarificar el pensamiento, conectando ideas, organizando y agrupando la información, dando una visión más general de la realidad y fijando más profundamente lo aprendido.

2. Reforzar la comprensión, pasando de la reproducción de lo memorizado a la interiorización y capacidad de asociación de ideas que ahora quedan en posesión del estudiante como propias.

3. Integrar nuevo conocimiento ya que, al asociar ideas, la mente va vinculando otras nuevas ya sean del exterior o de la propia persona que desarrolla su creatividad.

4. Identificar conceptos erróneos y proponer conceptos adecuados o útiles para un contexto. El aprendizaje a través del ensayo-error, faculta para dejar al descubierto asociaciones del conocimiento posibles o que merecen la pena ser investigadas.

\section{Aprender con metodologías performáticas o de acción}

En el lenguaje audiovisual, a la vez que pensamos y diseñamos también estamos per-formando la realidad. Simular situaciones y jugar con los procesos y las acciones, no solo desarrolla los juegos de representaciones y de símbolos, sino que genera espacios para expresar, comunicar y crear nuevas formas de acercamiento a la realidad.

Asociamos frecuentemente el juego a las edades más tempranas. Sin embargo, el juego es un simulador de la vida, una herramienta de aprendizaje y de ensayo de la realidad. En todas las etapas de la vida lo lúdico tiene un papel fundamental en nuestra vida. Lo festivo, que vincula la fiesta con el descubrimiento y la sorpresa, son herramientas que aportan más saberes a lo conocido.

Hay estrategias de innovación que favorecen la presencia de lo lúdico. Por ejemplo, los "juegos de rol" en el aula, que nos obligan a pensar en experiencias y ponernos en el lugar de otros, a la vez que diseñamos posibilidades y proyectamos situaciones nuevas. De esta manera, y en un ambiente placentero, se reta a nuestro pensamiento a que pruebe y descarte posibilidades hasta encontrar soluciones a los contextos descritos.

Por otro lado, la "gamificación" traslada la mecánica de los juegos al ámbito educativo con el fin de conseguir una profundidad mayor en el aprendizaje a través de las experiencias positivas que surgen del carácter lúdico y activo del juego. Trabaja y favorece la motivación, el esfuerzo, la fidelización o la cooperación, entre otros.

El pensamiento performativo o de acción, puede estar en todas las fases de un 


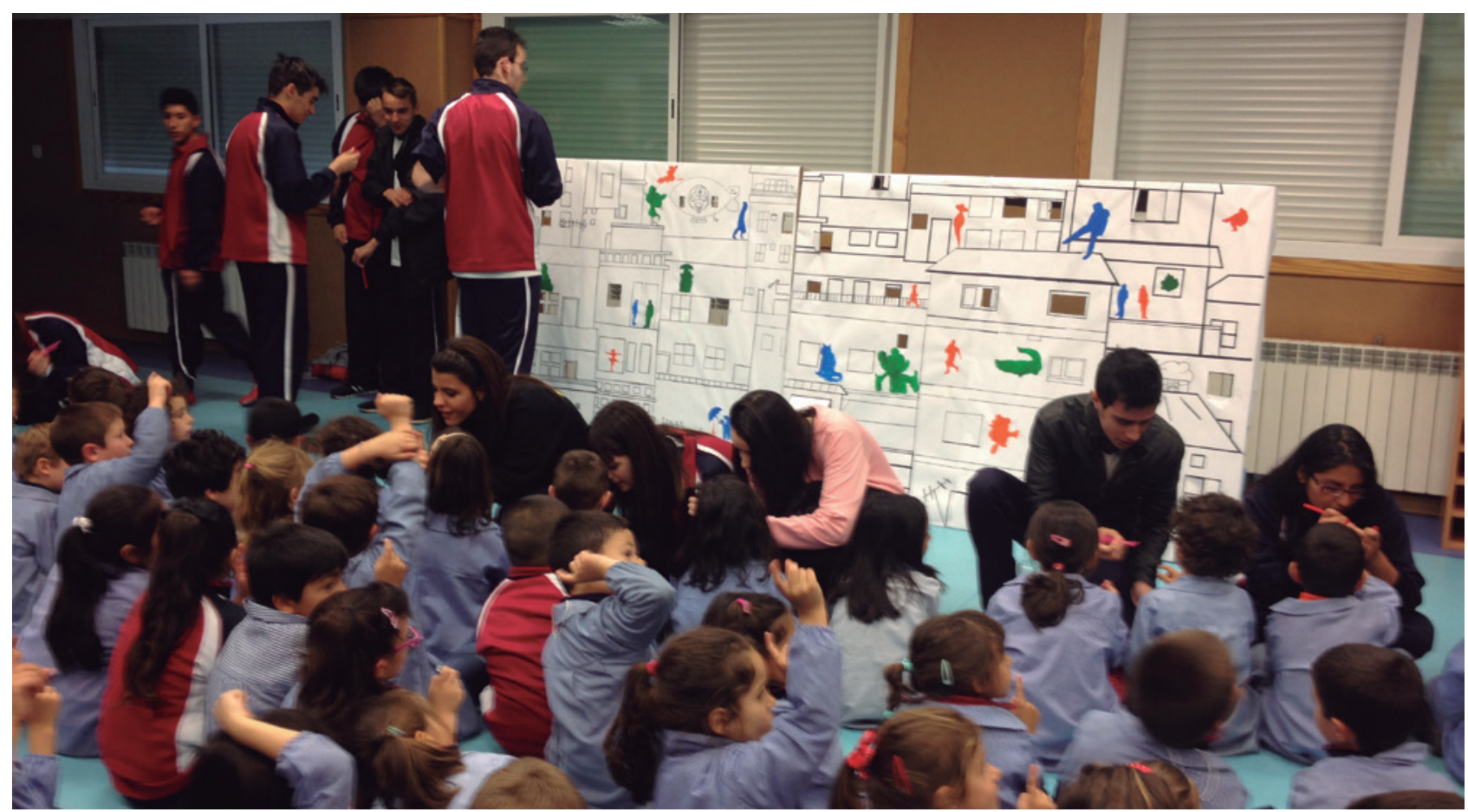

diseño o un proyecto, como el planteamiento de objetivos y análisis del contexto, o en la divergencia en la generación de ideas, que desemboca en la convergencia en soluciones prácticas. Permite, además, romper las barreras personales y mejorar la comunicación en el grupo, generando nuevas ideas, miradas y estrategias. Es una potente herramienta que desarrolla la creatividad del alumno.

\section{Aprendo porque disfruto}

Los estudios pedagógicos en innovación sugieren que las metodologías artísticas tienen el potencial de incrementar el deseo de los alumnos por aprender y aumentar el rendimiento en las clases. Explicar conceptos, vivir experiencias profundas que sean significativas y se fijen en su memoria, desarrollar la autonomía personal, son algunas de las competen-

\section{(D.) DARA SABER MÂS}

AcAso, M. (2017). Art Thinking. Barcelona: Paidós.

AcASO, M. (2013). rEDUvolution: hacer la revolución en la educación. Barcelona: Paidós

RoAm, D. (2012). Bla, bla, bla: Qué hacer cuando las palabras no funcionan. Madrid: Planeta.

Vivas, R. (2014). Pienso, luego dibujo. Introducción al pensamiento visual. Madrid: Lectyo. Recuperado de http://www.lectyo.com/ cias que son fundamentales para el mundo de hoy. Mejorar en ellos una mirada más globalizada y menos parcializada de la realidad, produciendo un efecto positivo sobre el sentido que se le da a la vida y los objetivos que nos ponemos en ella.

Para afrontar las muchas incógnitas del siglo XXI, necesitamos situar las artes como una estrategia educativa, para convertir la educación en un conjunto de procesos creativos que hacen de nosotros agentes de transformación aquí y ahora. Las metodologías artísticas o el art thinking, pueden ser el marco escolar que acompañe a los futuros ciudadanos a comprometerse con su entorno. El art thinking transforma al que mira, le hace más abierto, más empático, más activo. Nos empodera para tomar el mundo en nuestras manos y hacerlo mejor

\section{(-) HEMOS HABLADO DE \\ Aprendizaje visual; proceso de aprendizaje; arte; procesos creativos; creatividad; metodologías artísticas; pensamiento visual.}

Este artículo fue solicitado por PADRES Y MAESTROS en marzo de 2018, revisado y aceptado en junio de 2018. 